\title{
Assessing Adaptation Strategies for Extreme Heat: A Public Health Evaluation of Cooling Centers in Maricopa County, Arizona ${ }^{\mathscr{O}}$
}

\author{
Vjollca Berisha, ${ }^{\mathrm{a}}$ DAVid Hondula, ${ }^{\mathrm{b}}$ MAtThew Roach, ${ }^{\mathrm{c}}$ JessicA R. White, ${ }^{\mathrm{a}}$ \\ Benita McKinney, ${ }^{a}$ DARcie Bentz, ${ }^{\mathrm{d}}$ Ahmed Mohamed, ${ }^{\mathrm{a}}$ Joshua UebelherR, ${ }^{\mathrm{e}}$ \\ AND KATE GOODIN ${ }^{\mathrm{a}}$ \\ ${ }^{\text {a }}$ Office of Epidemiology, Maricopa County Department of Public Health, Phoenix, Arizona \\ ${ }^{\mathrm{b}}$ Center for Policy Informatics, and School of Geographical Sciences and Urban Planning, \\ Arizona State University, Tempe, Arizona \\ ${ }^{\mathrm{c}}$ Office of Environmental Health, Arizona Department of Health Services, Phoenix, Arizona \\ ${ }^{d}$ Public Health Associate Program, Centers for Disease Control and Prevention, Atlanta, Georgia \\ ${ }^{\mathrm{e}}$ Center for Policy Informatics, Arizona State University, Tempe, Arizona
}

(Manuscript received 22 March 2016, in final form 23 September 2016)

\begin{abstract}
Preventing heat-associated morbidity and mortality is a public health priority in Maricopa County, Arizona (United States). The objective of this project was to evaluate Maricopa County cooling centers and gain insight into their capacity to provide relief for the public during extreme heat events. During the summer of 2014, 53 cooling centers were evaluated to assess facility and visitor characteristics. Maricopa County staff collected data by directly observing daily operations and by surveying managers and visitors. The cooling centers in Maricopa County were often housed within community, senior, or religious centers, which offered various services for at least 1500 individuals daily. Many visitors were unemployed and/or homeless. Many learned about a cooling center by word of mouth or by having seen the cooling center's location. The cooling centers provide a valuable service and reach some of the region's most vulnerable populations. This project is among the first to systematically evaluate cooling centers from a public health perspective and provides helpful insight to community leaders who are implementing or improving their own network of cooling centers.
\end{abstract}

\section{Introduction}

Studies from around the world confirm that excessive heat exposure is associated with increased risk of morbidity and mortality (Curriero et al. 2002; Ostro et al. 2009; Pengelly et al. 2007; Semenza et al. 1996; Tobias et al. 2012a,b; Vaneckova et al. 2010). Aside from extreme cold, heat kills more people in the United States each year than all other weather-related hazards combined (Berko et al. 2014). The incidence of heat-related illness is significantly higher among older and younger groups, people with underlying chronic diseases, and homeless persons (Pellow 2000; Rey et al. 2007; Schwartz et al. 2004).

Supplemental information related to this paper is available at the Journals Online website: http://dx.doi.org/10.1175/WCAS-D-16-0033.s1.

Corresponding author e-mail: Vjollca Berisha, vjollcaberisha@ mail.maricopa.gov
One way to prevent adverse heat-associated outcomes is by going to a cooled indoor space (O'Neill et al. 2005; Semenza et al. 1996). However, socioeconomic status and geographical location may impede access to these spaces (Harlan et al. 2013; Hondula et al. 2015b; Reid et al. 2009). Populations that do not have a means to cool their living space have the highest danger of becoming ill and dying during extreme heat events (Harlan et al. 2006). Some governments and communities sponsor heat relief initiatives, including cooling centers, for atrisk groups.

Preventing heat-related illness is a public health priority in Maricopa County, Arizona. With nearly 4 million residents, Maricopa County (MC) is one of the largest metropolitan centers in the U.S. Southwest. It is home to Glendale, Mesa, Phoenix, Scottsdale, and other cities. The region experiences temperatures of more than $100^{\circ} \mathrm{F}$ from May through October; on average, temperatures reach a maximum of $110^{\circ} \mathrm{F} 26$ days $\mathrm{yr}^{-1}$ 
TABLE 1. List of evaluators and stakeholders by type, role, and number involved. The evaluators were responsible for the project as a whole; they developed the surveys, conducted the interviews, collected the data, analyzed the data, and developed recommendations. The stakeholders were a collective group of community members/organizations who were invested in the project through their interest in heat relief efforts.

\begin{tabular}{lllr}
\hline \hline \multicolumn{1}{c}{ Group } & \multicolumn{1}{c}{ Type } & \multicolumn{1}{c}{ Role } & Individuals involved $(N)$ \\
\hline $\begin{array}{l}\text { Maricopa County Department of Public Health } \\
\text { (MCDPH) }\end{array}$ & Local public health department & Evaluator & 10 \\
Arizona Department of Health Services (ADHS) & State health department & Evaluator & 5 \\
Arizona State University (ASU) & Academia & Evaluator & 4 \\
Maricopa Association of Governments (MAG) & Council of governments & Stakeholder & 2 \\
City of Phoenix Heat Relief Network (HRN) & Local government agency & Stakeholder & 1 \\
Cooling center facility managers & Community partners & Stakeholder & 53 \\
Cooling center visitors & Community members & Survey respondents & 658 \\
\hline
\end{tabular}

(Arguez et al. 2012). In chronically hot areas like Maricopa County, high temperatures exert a substantial toll on the public's health (Chuang et al. 2013; Hartz et al. 2013). The Maricopa County Department of Public Health $(\mathrm{MCDPH})$ reported an average of 87 heat-related deaths and more than 1000 heat-related illnesses annually between 2010 and 2014 (MCDPH 2015a).

The City of Phoenix and the Maricopa County Association of Governments (MAG) founded the Heat Relief Network (HRN) in 2005 following an extreme heat event that resulted in 35 deaths within 9 consecutive days. The HRN aimed to combat the health risks associated with extreme heat through initiatives such as water distribution stations and community cooling centers.

The objective of this evaluation was to assess MC cooling centers on the basis of their operations, services, costs, utilization, capacity, accessibility, communication strategies, and populations served.

\section{Methods}

In November 2013, MCDPH partnered with the Arizona Department of Health Services (ADHS) and Arizona State University (ASU) to form an evaluation team consisting of public health officials and academicians. The evaluation team used the Centers for Disease Control and Prevention (CDC) Framework for Program Evaluation as a model for this evaluation (Koplan et al. 1999). The ADHS Institutional Review Board declared this evaluation exempt based on it not collecting personally identifiable information and being strictly intended for program implementation. Members of the evaluation team completed training through the Collaborative Institutional Training Initiative (CITI) $\mathrm{Hu}-$ man Research Curriculum.

\section{a. Engage stakeholders}

In early 2014, the evaluation team met with multiple stakeholders, who provided valuable insight for designing the study and methods for administering surveys. Notable stakeholders, including ADHS, MCDPH, ASU, HRN, MAG, cooling center facility managers, and community members, were involved in the evaluation process (Table 1 ). In April 2014, the evaluation team presented the proposal at the HRN Annual Kick-off Meeting.

\section{b. Describe the program}

After meeting with stakeholders, the evaluation team summarized activities and outcomes in a logic model (Fig. 1). HRN's ultimate goal is to prevent heat-related morbidity and mortality (MAG 2015). It is a voluntary network of service providers, faith-based groups, municipalities, businesses, and caring citizens. Network participants provide hydration and heat refuge for people in need. Sites in the network serve as collection points for donations and distribution of bottled water and items to meet basic needs. Many sites also provide safe, cool, indoor environments for the public and are registered by HRN as cooling centers.

\section{c. Focus the evaluation design}

The evaluation focused on key elements to help stakeholders understand cooling center operations and populations served. One portion of the evaluation measured the cooling centers' services offered, costs, utilization, capacity, accessibility, and communication strategies. The other portion of the evaluation focused on the population served by capturing the characteristics and opinions of cooling center visitors.

\section{d. Gather credible evidence}

In March 2014, the evaluation team developed three instruments to capture information about the 56 registered cooling center facilities and their visitors: 1) an observational survey, 2) a facility manager survey, and 3) a visitor survey (provided in the supplemental material). The instruments were pilot-tested in May 2014. Field teams of three members each were trained in 
Situation: High morbidity and mortality due to environmental heat exposure

\begin{tabular}{|c|c|c|c|c|c|}
\hline \multirow{2}{*}{\begin{tabular}{l}
\multicolumn{1}{c}{ Inputs (Resources) } \\
$\begin{array}{l}\text { Resources of cooling } \\
\text { centers: }\end{array}$
\end{tabular}} & \multicolumn{2}{|c|}{ Outputs } & \multicolumn{3}{|c|}{ Outcomes - Impact } \\
\hline & Activities & Participation & Short & Medium & Long \\
\hline $\begin{array}{l}\text { Resources of cooling } \\
\text { centers: } \\
\text { - Staff } \\
\text { - Facility } \\
\text { - Water donations } \\
\text { - Monetary donations } \\
\text { - Time }\end{array}$ & $\begin{array}{l}\text { What Do They Do? } \\
\text { - Providing cooling } \\
\text { space } \\
\text { - Offering health and } \\
\text { human services } \\
\text { - Distribution of water } \\
\text { - Provide food } \\
\text { - Provide amenities } \\
\text { - Recreation } \\
\text { - Provide community } \\
\text { education } \\
\text { - Provide services } \\
\text { primarily during } \\
\text { business hours } \\
\text { - Increase community } \\
\text { outreach }\end{array}$ & $\begin{array}{l}\text { Who Do They Reach? } \\
\text { - Those without air } \\
\text { conditioning or not } \\
\text { able to afford } \\
\text { - Those in need of } \\
\text { utility assistance or } \\
\text { unemployed } \\
\text { - Those in need for } \\
\text { water and/or food } \\
\text { - Children out of } \\
\text { school } \\
\text { - All ages }\end{array}$ & $\begin{array}{l}\text { Extend } \\
\text { service to } \\
\text { weekend and } \\
\text { evening hours } \\
\text { Decrease } \\
\text { physical } \\
\text { barriers for } \\
\text { vulnerable } \\
\text { populations }\end{array}$ & $\begin{array}{l}\text { Increase cooling center use } \\
\text { by vulnerable populations }\end{array}$ & $\begin{array}{l}\text { Reduce morbidity and } \\
\text { mortality }\end{array}$ \\
\hline
\end{tabular}

FIG. 1. Cooling center evaluation logic model, Maricopa County, 2014.

professionalism and cultural competency with community members, interviewing procedures, and survey administration.

The observational survey was a 12 -item instrument that assisted field teams with collecting objective information about the facility's type, location, visibility, accessibility, capacity, utilization, and amenities. Site visits were conducted during weekday business hours in June and July 2014.

The in-person facility manager survey included 30 questions that captured information about each facility's services, necessary supplies, approximate capacity, and their perception of average daily utilization. Interviews were conducted between May and August 2014. Four hours were allotted to conduct the observational and facility manager surveys at each facility.

Between June and September 2014, facility managers made available, in English and Spanish, a 24-item, openand closed-ended, self-administered paper survey for visitors. Spanish surveys were provided because $30 \%$ of the Maricopa County population is Hispanic or Latino and 9.9\% report speaking English less than "very well" (U.S. Census Bureau 2010). The survey captured visitors' demographics and cooling center utilization, as well as their perceptions of heat vulnerability and cooling center accessibility. The evaluation team collected surveys weekly. Efforts were made to ensure visitors completed the survey only once so as to eliminate any duplicate surveys.
Quantitative data were summarized with descriptive statistics, and qualitative data were coded based on content and themes. Data entry, quality control, and analyses were completed using Qualtrics, Microsoft Excel, and SAS Enterprise Guide (version 5.1) software.

\section{e. Justify conclusions}

Public health officials recommend providing designated cooling centers for vulnerable community members; however, neither these recommendations nor a list of standards for operating the centers has been provided in previous studies (Houghton 2013; California Climate Action Team 2013). Using results from this evaluation, the team developed a list of key elements for operating a successful cooling center (Table 2).

\section{f. Ensure use and share lessons learned}

Preliminary evaluation findings were shared with stakeholders periodically. Stakeholders provided feedback, which helped guide analyses. In September 2015, the final results were summarized into three written reports and an oral presentation.

After the cooling center evaluation project was finished, several other projects were initiated to further understand and address the issue of chronic heat exposure in Maricopa County. The MCDPH initiated a Community Assessment for Public Health Emergency Response (CASPER) survey and a survey of homebound individuals 
TABLE 2. Key elements for operating a successful cooling center.

\begin{tabular}{|c|c|}
\hline Key elements & Details \\
\hline \multicolumn{2}{|l|}{ Facility characteristics } \\
\hline Visibility & $\begin{array}{l}\text { Advertise by posting a considerable amount of signage, which can be visible from streets } \\
\text { and public transit }\end{array}$ \\
\hline Hours of operation & $\begin{array}{l}\text { Plan to operate during the hottest part of the day and provide extended hours while } \\
\text { excessive heat warnings are in effect; indicate hours clearly }\end{array}$ \\
\hline Easily accessible & $\begin{array}{l}\text { All facilities should be compliant with the American Disability Act (ADA); centers in } \\
\text { the network should be near public transportation and have enough space for parking }\end{array}$ \\
\hline Capacity & Provide adequate seating \\
\hline Services offered & Provide water, amenities, and restrooms \\
\hline Safe environment & Develop security plans for diverting any unsafe or unwanted events/situations \\
\hline Communication & $\begin{array}{l}\text { Effectively communicate between network coordinators, other facilities, facility staff, } \\
\text { and visitors; provide facility location maps that are easily accessible }\end{array}$ \\
\hline \multicolumn{2}{|l|}{ Managers and staff characteristics } \\
\hline Cultural competence & $\begin{array}{l}\text { Managers/staff should understand and be sensitive to the needs of the various pop- } \\
\text { ulations that they serve }\end{array}$ \\
\hline Sufficiently trained and knowledgeable & $\begin{array}{l}\text { Managers/staff should know emergency plans and procedures and how to respond in } \\
\text { emergency situations }\end{array}$ \\
\hline \multicolumn{2}{|l|}{ Visitor characteristics } \\
\hline Diverse populations & Provide appropriate services for people of all ages, genders, and cultures \\
\hline Vulnerable populations & $\begin{array}{l}\text { Provide services for those lacking air conditioned spaces and/or economic resources and } \\
\text { those with special needs }\end{array}$ \\
\hline
\end{tabular}

to understand needs and barriers during extreme heat events. Also, ASU is developing a tool to help visualize HRN visitation dynamics.

\section{Results}

During the summer of 2014, 56 cooling centers were registered with the HRN. One facility was no longer in operation, and two did not respond to requests to participate in the evaluation; these three facilities were excluded from the study. The field evaluation teams conducted observational surveys at 53 facilities (Fig. 2) and interviewed 52 managers. The visitor surveys were completed by 658 participants from 22 cooling centers. Complete survey results are available on the MCDPH website (MCDPH 2015b).

\section{a. Operations}

The organizations that operate cooling centers have primary functions other than providing a cooled space for the community. A majority of the facilities were categorized by managers as community, senior, or religious centers (Table 3). Other cooling centers were operating within government office buildings, private business spaces, nonprofit organizations, parks and recreation buildings, homeless shelters, or other venues.

At least 48 (92\%) of the cooling centers were operating each weekday, but only 20 were operating on Saturdays and 11 on Sundays (Table 3). Most cooling centers were available during normal weekday business hours $(91 \%)$. Three facilities were open to the public 24 hours a day.

According to facility managers, these were the top reasons they wanted their facilities to become cooling centers: 1) they wanted to be involved with addressing community need $(23 ; 44 \%)$ and 2 ) they recognized the high incidence of extreme heat-related deaths (16; $31 \%)$. A majority of the cooling centers $(32 ; 60 \%)$ have been operating for less than 6 years.

\section{b. Services offered}

All cooling centers provided a cooled environment for their visitors. While the observational surveys were being conducted, outdoor maximum daily temperatures often approached $110^{\circ} \mathrm{F}$. The team measured indoor temperatures $\leq 79^{\circ} \mathrm{F}$ at $94 \%$ of the cooling centers. Two facilities had indoor temperatures between $85^{\circ}$ and $89^{\circ} \mathrm{F}$. Nearly all facilities were cooled with central air conditioning, and more than one-quarter of the facilities used both fans and central air conditioning (Table 3).

Facilities provided free bottled water and water fountains. Managers reported that they distributed a median of 25 bottles of water (range: 0-1300) on a typical day (Table 3). Seventeen (33\%) cooling center managers reported running out of bottled water at some point. When facilities ran out of bottled water, they purchased more water or used tap water.

Additional services varied, depending on the organizations' primary functions. Facilities provided community members with access to restrooms, vending machines, 


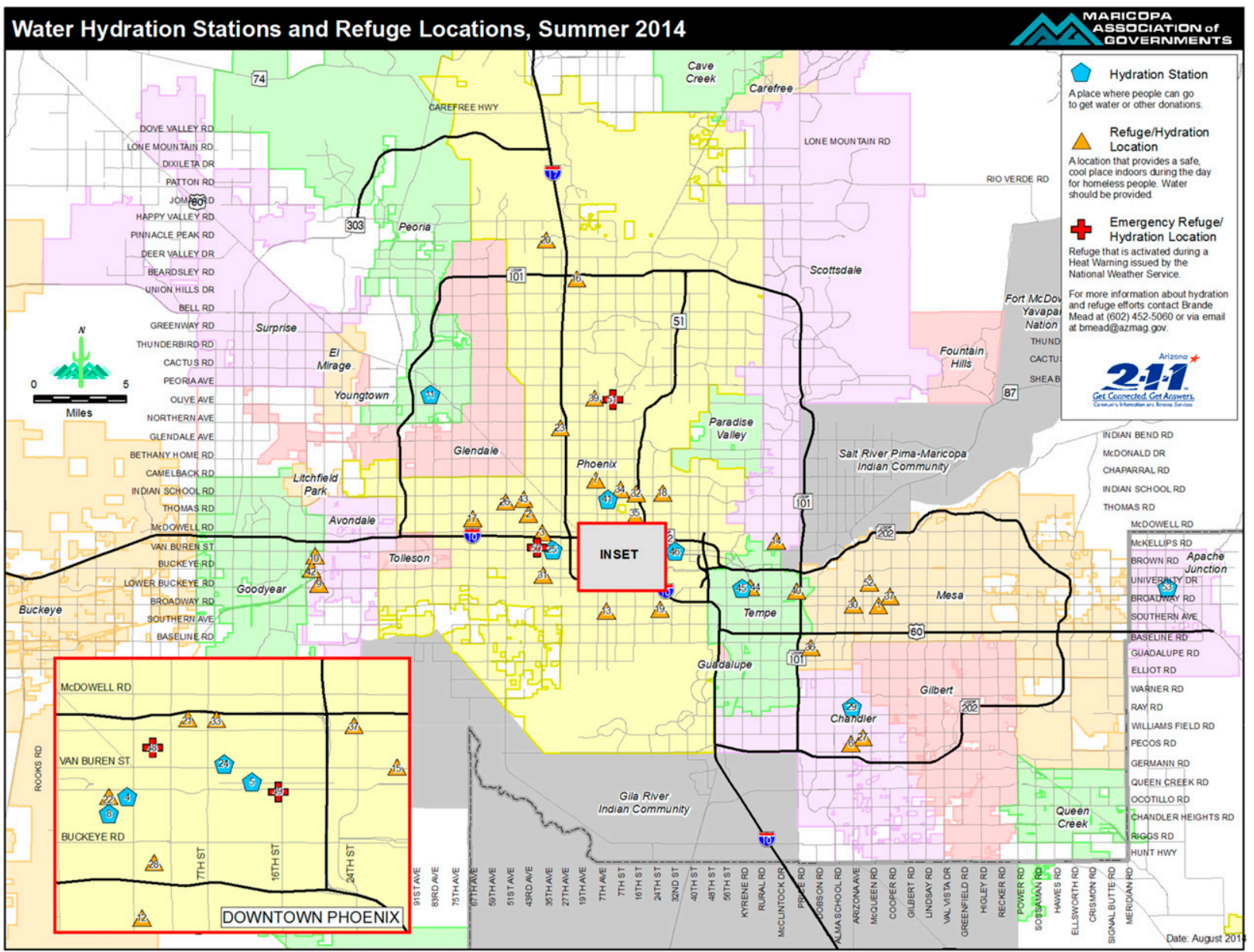

FIG. 2. Map of heat relief network cooling centers, Phoenix, Arizona, 2014.

food and snacks, electrical outlets, wireless Internet access, indoor recreation or play areas, and books, magazines, or games (Table 3). Human services included community adult education, child care/childhood education, employment and financial services, and religious services.

Visitor survey respondents provided a variety of reasons for visiting cooling centers. Of visitors, $22 \%$ (143) reported that they visited the facility to get away from the heat. Many respondents reported that they visited the center to obtain food, water, or shelter and to use the organization's other services (Table 4).

\section{c. Costs}

More than half of the facility managers reported no additional operational costs associated with their facility serving as a cooling center (Table 3 ). However, some facility managers reported that at least one additional staff member/volunteer was needed to support cooling center services. In addition, some facilities incurred costs due to additional staff hours, water purchases, and higher utility bills. To offset additional costs, some facilities received monetary assistance and/or water, food, and clothing donations from nonprofit organizations, churches, individuals, government agencies, the HRN, or private businesses. However, managers did not report costs as a major barrier for participating in the HRN.

Facility managers indicated that they were constrained by limited operating hours $(18 ; 35 \%)$, staffing $(11 ; 21 \%)$, and budgets $(8 ; 15 \%)$. If resources were unlimited, managers reported that they would extend their operating season to include March and April, as well as provide housing, restrooms, more items (e.g., fans, misters), and protective weather gear (e.g., hats, sunscreen).

\section{d. Utilization}

Managers acknowledged that utilization of their cooling center varied by month, day of the week, time of day, and temperature. According to facility manager estimates, approximately 1500-2000 individuals use cooling centers each day-typically for periods of less than one hour-for heat relief and other services. 
TABLE 3. Characteristics of cooling centers in Maricopa County, $2014(N=53)$. Note: Most categories were not mutually exclusive. An asterisk (*) indicates that data are from an observational survey.

\begin{tabular}{|c|c|}
\hline Characteristic & $N(\%)$ \\
\hline \multicolumn{2}{|l|}{ Operations } \\
\hline \multicolumn{2}{|l|}{ Primary function of facility } \\
\hline Community center & $16(31 \%)$ \\
\hline Senior center & $16(31 \%)$ \\
\hline Religious center & $7(13 \%)$ \\
\hline $\begin{array}{l}\text { Other (e.g., rehab/recovery, parks and } \\
\text { recreation, homeless shelter, } \\
\text { government office building) }\end{array}$ & $13(25 \%)$ \\
\hline \multicolumn{2}{|l|}{ Weekend availability } \\
\hline Saturday & $20(39 \%)$ \\
\hline Sunday & $11(21 \%)$ \\
\hline \multicolumn{2}{|l|}{ Services } \\
\hline \multicolumn{2}{|l|}{$\begin{array}{l}\text { Supplies and services provided to visitors } \\
\text { beyond a cooled space and water }\end{array}$} \\
\hline Food/snacks & $38(72 \%)$ \\
\hline Health and human services & $31(58 \%)$ \\
\hline Housing/utility bill assistance & $24(45 \%)$ \\
\hline Homeless services & $10(19 \%)$ \\
\hline \multicolumn{2}{|l|}{ On-site cooling systems } \\
\hline Central air conditioning & $52(98 \%)$ \\
\hline Fans/central air conditioning & $14(26 \%)$ \\
\hline Outdoor space & $3(6 \%)$ \\
\hline Window unit air conditioning & $2(4 \%)$ \\
\hline \multicolumn{2}{|l|}{ Average water distribution per day } \\
\hline 1 case (i.e., 24 bottles) & $24(49 \%)$ \\
\hline $2-3$ cases & $13(27 \%)$ \\
\hline $4+$ cases & $12(25 \%)$ \\
\hline \multicolumn{2}{|l|}{ Costs } \\
\hline $\begin{array}{l}\geq 1 \text { additional staff needed to operate } \\
\text { cooling center (above normal staffing) }\end{array}$ & $28(54 \%)$ \\
\hline \multicolumn{2}{|l|}{$\begin{array}{l}\text { Costs associated with serving as a } \\
\text { cooling center }\end{array}$} \\
\hline No additional costs & $33(62 \%)$ \\
\hline Staff hours & $12(23 \%)$ \\
\hline Water & $9(17 \%)$ \\
\hline Utilities & $8(15 \%)$ \\
\hline \multicolumn{2}{|l|}{ Source of bottled water } \\
\hline $\begin{array}{l}\text { Received through Phoenix Heat Relief } \\
\text { Network only }\end{array}$ & $12(23 \%)$ \\
\hline Received through external donations only & $14(27 \%)$ \\
\hline $\begin{array}{l}\text { Received through Phoenix Heat Relief } \\
\text { Network and external donations }\end{array}$ & $26(50 \%)$ \\
\hline \multicolumn{2}{|l|}{ Utilization } \\
\hline \multicolumn{2}{|l|}{$\begin{array}{l}\text { Estimated average amount of time spent at } \\
\text { cooling center by visitors }\end{array}$} \\
\hline$<1 \mathrm{~h}$ & $30(60 \%)$ \\
\hline$>4 \mathrm{~h}$ & $8(16 \%)$ \\
\hline \multicolumn{2}{|l|}{ Capacity } \\
\hline \multicolumn{2}{|l|}{ Estimated total capacity of cooling center } \\
\hline $1-50$ people (small) & $18(36 \%)$ \\
\hline $51-200$ people (medium) & $18(36 \%)$ \\
\hline$>200$ people (large) & $14(28 \%)$ \\
\hline \multicolumn{2}{|l|}{ Number of available chairs observed* } \\
\hline$\leq 24$ chairs & $20(38 \%)$ \\
\hline 25-99 chairs & $20(38 \%)$ \\
\hline$\geq 100$ chairs & $13(25 \%)$ \\
\hline
\end{tabular}

TABLE 3. (Continued)

\begin{tabular}{|c|c|}
\hline Characteristic & $N(\%)$ \\
\hline \multicolumn{2}{|l|}{$\begin{array}{l}\text { Average percentage of capacity used by } \\
\text { visitors daily }\end{array}$} \\
\hline$\leq 25 \%$ capacity is used daily & $(46 \%)$ \\
\hline $26 \%-50 \%$ & $(17 \%)$ \\
\hline $51 \%-75 \%$ & $(20 \%)$ \\
\hline$>75 \%$ capacity used daily & $(17 \%)$ \\
\hline \multicolumn{2}{|l|}{ Accessibility and accommodations } \\
\hline $\begin{array}{l}\text { Cooling center easily accessible for } \\
\text { those with a physical disability* }\end{array}$ & $47(90 \%)$ \\
\hline \multicolumn{2}{|l|}{$\begin{array}{l}\text { Accommodations for individuals } \\
\text { with physical disability }\end{array}$} \\
\hline $\begin{array}{l}\text { Compliant with Americans with } \\
\text { Disabilities Act (ADA) }\end{array}$ & $29(56 \%)$ \\
\hline $\begin{array}{l}\text { Not ADA compliant but able to } \\
\text { accommodate }\end{array}$ & $16(31 \%)$ \\
\hline \multicolumn{2}{|l|}{ Accommodations for homeless individuals } \\
\hline $\begin{array}{l}\text { Provide supplies such as water, food, } \\
\text { and clothing }\end{array}$ & $20(38 \%)$ \\
\hline $\begin{array}{l}\text { Refer to services such as shelters, mental } \\
\text { health care, and food banks }\end{array}$ & $14(27 \%)$ \\
\hline \multicolumn{2}{|l|}{$\begin{array}{l}\text { Accommodations for non-English-speaking } \\
\text { individuals }\end{array}$} \\
\hline Staff translates in Spanish & $41(79 \%)$ \\
\hline External translation services & $14(27 \%)$ \\
\hline \multicolumn{2}{|l|}{ Communication strategies } \\
\hline \multicolumn{2}{|l|}{$\begin{array}{l}\text { Communication channel for alerting } \\
\text { public about cooling center }\end{array}$} \\
\hline Word of mouth & $28(54 \%)$ \\
\hline Printed materials & $17(33 \%)$ \\
\hline Internet & $17(33 \%)$ \\
\hline Hanging materials & $15(29 \%)$ \\
\hline $\begin{array}{l}\text { Clearly visible indicator on exterior of } \\
\text { building that the facility is a cooling center } \\
\text { (e.g., sticker, emblem, sign on window)* }\end{array}$ & $17(32 \%)$ \\
\hline Signage in both English and Spanish* & $7(41 \%)$ \\
\hline
\end{tabular}

Cooling center visitor survey respondents were demographically diverse (Table 4). Nearly 500 respondents were unemployed and one-third were not living at a permanent residence. Many respondents did not have access to an air conditioner at their home or were not using it because of utility costs or unit disrepair. More than 200 respondents reported that they had chronic medical conditions, such as cardiovascular diseases, respiratory diseases, and diabetes. Half of the survey respondents reported that they believed high summer temperatures put their health at risk.

Of facility respondents, $42 \%$ (21) reported never having to turn someone away from services. Of the remaining respondents, the most frequently mentioned reasons for turning people away were safety and behavior within their facility (56\%) and/or intoxication (32\%). Most visitors reported feeling comfortable (92\%) and safe (93\%) at cooling centers. 
TABLE 4. Characteristics of cooling center visitors in Maricopa County, $2014(N=658)$.

\begin{tabular}{|c|c|}
\hline Characteristic & $N(\%)$ \\
\hline \multicolumn{2}{|l|}{ Demographics } \\
\hline Gender, female & $356(59 \%)$ \\
\hline \multicolumn{2}{|l|}{ Age group } \\
\hline$<18$ years & $32(5 \%)$ \\
\hline $18-44$ years & $242(40 \%)$ \\
\hline $45-64$ years & $194(32 \%)$ \\
\hline$\geq 65$ years & $143(23 \%)$ \\
\hline \multicolumn{2}{|l|}{ Race/ethnicity } \\
\hline White & $238(39 \%)$ \\
\hline Hispanic & $196(33 \%)$ \\
\hline African American & $110(18 \%)$ \\
\hline Native American & $48(8 \%)$ \\
\hline Asian or Pacific Islander & $11(2 \%)$ \\
\hline Primary language - English only & $468(82 \%)$ \\
\hline Spanish only & $60(10 \%)$ \\
\hline Unemployed & $497(84 \%)$ \\
\hline \multicolumn{2}{|l|}{ Household } \\
\hline Currently living at permanent residence & $390(67 \%)$ \\
\hline Air conditioning unit at place of living & $336(89 \%)$ \\
\hline Not currently living at permanent residence & $192(33 \%)$ \\
\hline Air conditioning unit at place of living & $87(64 \%)$ \\
\hline \multicolumn{2}{|l|}{$\begin{array}{l}\text { Among visitors with air conditioning unit at } \\
\text { place of living }\end{array}$} \\
\hline Able to use the air conditioning unit & $408(73 \%)$ \\
\hline $\begin{array}{l}\text { Rarely use air conditioning unit because } \\
\text { it costs too much }\end{array}$ & $86(16 \%)$ \\
\hline Air conditioning unit is broken & $21(4 \%)$ \\
\hline Have used utility assistance program & $138(25 \%)$ \\
\hline \multicolumn{2}{|l|}{ Vulnerability } \\
\hline \multicolumn{2}{|l|}{ Awareness of excessive heat warnings } \\
\hline Usually find out by television & $381(61 \%)$ \\
\hline Usually find out by word of mouth & $138(22 \%)$ \\
\hline Usually find out by radio & $117(19 \%)$ \\
\hline $\begin{array}{l}\text { Usually do not know when warnings } \\
\text { are issued }\end{array}$ & $97(15 \%)$ \\
\hline Chronic medical condition & $240(41 \%)$ \\
\hline $\begin{array}{l}\text { Feel that health is at risk due to high } \\
\text { summer temperatures }\end{array}$ & $281(50 \%)$ \\
\hline \multicolumn{2}{|l|}{ Communication channels } \\
\hline \multicolumn{2}{|l|}{$\begin{array}{l}\text { Communication channel for finding } \\
\text { cooling center }\end{array}$} \\
\hline Saw location in person & $195(29 \%)$ \\
\hline Word of mouth & $185(28 \%)$ \\
\hline Previous knowledge/awareness of location & $142(21 \%)$ \\
\hline Through a local organization & $63(10 \%)$ \\
\hline \multicolumn{2}{|l|}{ Accessibility } \\
\hline \multicolumn{2}{|l|}{ Transportation to cooling center } \\
\hline Personal vehicle & $233(33 \%)$ \\
\hline Walked & $226(32 \%)$ \\
\hline Public transportation (e.g., bus, light rail) & $158(23 \%)$ \\
\hline \multicolumn{2}{|l|}{ Services } \\
\hline \multicolumn{2}{|l|}{ Reason for visit } \\
\hline Get away from the heat & $143(22 \%)$ \\
\hline $\begin{array}{l}\text { Center services (e.g., food, water, recreation, } \\
\text { shelter, utility assistance) }\end{array}$ & $501(78 \%)$ \\
\hline \multicolumn{2}{|l|}{ Utilization } \\
\hline First visit to cooling center this summer & $225(36 \%)$ \\
\hline
\end{tabular}

TABLE 4. (Continued)

\begin{tabular}{lc}
\hline \multicolumn{1}{c}{ Characteristic } & $N(\%)$ \\
\hline \multicolumn{1}{c}{ Average number of visits to a cooling } \\
$\quad$ center during typical summer \\
$1-2$ & \\
$\geq 3$ & $130(33 \%)$ \\
Average amount of time spent at cooling center & $265(67 \%)$ \\
$<1 \mathrm{~h}$ & $200(40 \%)$ \\
$>4 \mathrm{~h}$ & $115(23 \%)$ \\
\hline
\end{tabular}

\section{e. Capacity}

The field evaluation teams could only find maximum occupancy signs posted in seven facilities, so capacity was based on facility manager estimates. The manager of the smallest facility estimated that its cooling center could accommodate eight people, while the manager of the largest facility estimated a capacity of 1785 people. Cooling center spaces ranged from single small rooms within the facility to multiple large spaces, such as gymnasiums (Table 3).

Some managers reported that their facilities operated at less than $25 \%$ capacity each day, while other managers reported operating at greater than $75 \%$ capacity each day (Table 3). The field evaluation teams observed that $20 \%$ (10) of facilities were crowded at the time of visit.

\section{f. Accessibility and accommodations}

Visitors reported that they drove their personal vehicle, walked, or used public transportation to get to the facility (Table 4). The field evaluation teams assessed that $90 \%$ of the facilities were easy to see, approach, enter, use, or understand for all people, including those with disabilities. Five cooling centers were not easily accessible because they had low visibility from major streets and sidewalks, inaccessible gates, or an unclear entrance. Managers reported that they strived to make accommodations for individuals with physical disabilities, non-English speakers, and homeless persons (Table 3). Most facilities (96\%) had established a protocol—which included calling 911, relying on staff with relevant medical training, involving management, and/or filing incident reports-for addressing emergencies.

\section{g. Communication strategies}

Facility managers reported using various communication channels to alert the public about their cooling center (Table 3). Popular communication strategies included government and community organization website messages, e-mail blasts, social media posts, regional newspaper ads, religious and community newsletters, posters, public service announcements, and pamphlets within utility bills. Several facilities (15\%) directed their 
advertisements at vulnerable populations, such as seniors, low-income families, and homeless persons. Some centers relied on the HRN to advertise their cooling center service; a majority of centers relied on word of mouth. Although several managers mentioned that they posted signs on their facilities' exteriors to inform people about their cooling center service, the field teams noted that only $33 \%$ (17) had a visible sign. The sign indicated 1) that the cooling center was an HRN participant providing refuge and water, 2) operating hours, 3) tips for preventing heatrelated illness, and 4) information for accepting donations. Of these 17 facilities seven (41\%) had signs that were available in both English and Spanish.

Visitor surveys revealed that the most common ways visitors found out about cooling centers were by seeing a facility's location $29 \%$ (195), word of mouth $28 \%$ (185), and through local organizations 10\% (63) (Table 4 ). Less than $5 \%$ of respondents indicated that they found out about the cooling center they were visiting from television, radio, newspaper, Internet, and/or e-mail.

The National Weather Service issues excessive heat warnings for the public-warnings that may motivate the public to seek cooling centers. Visitors learned about these warnings via television, word of mouth, and radio (Table 4). Of respondents, $15 \%$ were not aware of when excessive heat warnings were issued.

\section{h. HRN communication}

Facility managers had varying levels of communication with the HRN and other participating cooling centers. While $19 \%$ of the managers were unsure of their facility's current level of communication with the HRN, about one-third of the facilities had minimal communication with the HRN, and $12 \%$ had no communication with the HRN. A quarter of the facilities were satisfied with the current level of communication, and $5 \%$ reported that they did not know how to contact the HRN.

\section{Discussion}

Few studies have measured the effectiveness of climate adaptation efforts on public health (Hess et al. 2014). This is the first project of this scope and magnitude to evaluate community-sponsored cooling centers from a public health perspective (Bassil and Cole 2010; Boeckmann and Rohn 2014; Hondula et al. 2015a; Woodward et al. 2014). This evaluation is a first step toward understanding the facilitators and barriers for operating a specific local climate adaptation program and evaluating the public benefit. Findings from this evaluation provide insight for other large urban communities, particularly in hot settings.
Most cooling centers operated in facilities that already provided health or human services for the community. The facilities tended to operate the cooling center during their normal weekday hours of operation; however, summer minimum overnight temperatures are often $\geq 80^{\circ} \mathrm{F}$, which leaves many individuals vulnerable to nighttime heat stress. In addition, only three facilities opened on weekends, which left many in the community vulnerable to high temperatures on Saturdays and Sundays. The current hours of operation are not always optimal for preventing heat-related illness; therefore, many individuals would benefit from alternate weekly and extendedhour schedules (Uebelherr et al. 2015). Currently, the costs of operation appeared to be offset by monetary and water donations. Although additional hours might benefit the community they likely will increase operational costs, and additional funding sources would need to be explored.

Seventy-eight percent of respondents visited cooling centers to use the primary services provided by the facility rather than visiting the center to seek refuge from the heat. However, facility staff effectively integrated cooling center refuge services with primary services offered. Despite visitation motives, hundreds of free bottles of water distributed to cooling center visitors each day helped combat the risk of dehydration and heat illness.

Across the network, cooling centers had the capacity to accommodate more visitors than currently served. The evaluation team estimated that up to 2000 individuals used the cooling centers each day.

The cooling centers appear to reach some of the region's most vulnerable populations. Many visitors were unemployed, lacked a permanent residence, had no reliable access to home air conditioning, and/or had a chronic medical condition.

High summer temperatures pose risks for everyone, and certain populations are especially vulnerable during extreme heat events. Surprisingly, half of respondents did not believe high summer temperatures could put their health at risk. Alternative messaging strategies or improvements on the existing campaigns are needed to enhance community knowledge about the widespread health risks of excessive heat.

Cooling center use might be improved if signs were present or more visible to attract potential visitors. In addition, knowledge and use of cooling centers might improve by promoting cooling center services through distributing current information and accurate maps of cooling center locations throughout the community using electronic and nonelectronic channels such as text messaging or community news boards respectively. Marketing and outreach coordinators should consider that almost a quarter of the visitors used public transportation to arrive at the cooling centers, indicating that collaboration with 
public transit agencies to advertise the cooling centers might boost use.

This evaluation revealed common challenges faced by cooling center managers. Many managers were not sure how to 1) increase their participation with the HRN, 2) adequately advertise their status as a cooling center, or 3) provide appropriate public health education to their visitors. Other managers felt that they were limited to operating during normal business hours, even though community members might have needed the service at other times. The challenges identified in the HRN are consistent with several of the key barriers to effective climate adaptation found in the public health literature (Huang et al. 2011).

The evaluation does have several limitations that warrant discussion. First, cooling center visitor sampling was not random. Since findings were from a convenience sample, they might not be representative of all cooling center visitors and might not be generalizable to similar urban centers. Second, vulnerable community members who were not aware of or unable to access cooling centers were not included in the survey. Therefore, the data did not capture information from individuals who likely have the greatest need for cooling centers. Third, it was difficult to differentiate facilities' primary services from the cooling center services. Finally, MCDPH promotes and encourages the use of informal cooling centers, such as libraries, indoor malls, public transit lines, and restaurants, which are abundant and convenient and offer some entertainment or activities. These non-HRN cooling centers are likely meeting some of the county's need for heat relief and serving people with different socioeconomic statuses. Thus, it should be noted that the demographics and social outcomes of visitors to official HRN cooling centers may not be representative of all community members who seek heat relief (Chester et al. 2015; Fraser et al. 2015).

An intermediate-term goal of the cooling centers was to reduce heat exposure among area residents. This could be accomplished by increasing HRN or other coordinating support to facilities outside the Phoenix city limits, extending service hours, and increasing locations. The surveys did not formally measure individuals' heat exposure inside or outside the cooling centers or assess whether the geographical distribution or capacities of cooling centers were effectively reducing heat exposure across the region. To measure heat exposure objectively, participants could use personal sensors that capture experienced temperatures continuously (Bernhard et al. 2015; Kuras et al. 2015). Furthermore, a communitywide survey could reveal gaps in coverage and quantify the unmet need for reducing heat exposure.

In the long term, the evaluation team can support the cooling centers, HRN, and MAG by better understanding the reach of the cooling centers, measuring the impacts of cooling center access, and monitoring the changes in both over time. Continued evaluation of cooling centers is important for stakeholders to understand public health impact, examine return on investment, and determine whether cooling centers are reaching long-term goals.

In conclusion, cooling centers provide a valuable public health service to the region. This project was successful because public health officials, academicians, HRN coordinators, and facility managers provided unique insight and effort for measuring cooling center operations, utilization, and visitor characteristics. Through this collaboration, stakeholders have the basis for improving HRN and cooling center operations to maximize the public health impact.

Acknowledgments. The authors gratefully acknowledge the Arizona Department of Health Services; Arizona State University Center for Policy Informatics and School of Geographical Sciences and Urban Planning; the Maricopa County Department of Public Health staff and interns; and the Centers for Disease Control and Prevention public health associates for assistance with data collection and analysis, as well as Kristina Blea, City of Phoenix Heat Relief Network, and Brande Mead, Maricopa Association of Governments, for supporting the project. The authors would also like to thank cooling center facility managers and visitors for contributions in survey completion. Members of the project were partially supported by the Virginia G. Piper Trust Health Policy Informatics Initiative at Arizona State University, the Centers for Disease Control and Prevention Building Resilience Against Climate Effects (BRACE) Program in Arizona under Grant 1UE1EH001119-01, and the National Science Foundation under Grant BCS-1026865, Central Arizona-Phoenix Long Term Ecological Research Program (CAP LTER).

\section{REFERENCES}

Arguez, A., I. Durre, S. Applequist, R. S. Vose, M. F. Squires, X. Yin, R. R. Heim Jr., and T. W. Owen, 2012: NOAA's 19812010 U.S. climate normals: An overview. Bull. Amer. Meteor. Soc., 93, 1687-1697, doi:10.1175/BAMS-D-11-00197.1.

Bassil, K. L., and D. C. Cole, 2010: Effectiveness of public health interventions in reducing morbidity and mortality during heat episodes: A structured review. Int. J. Environ. Res. Public Health, 7, 991-1001, doi:10.3390/ijerph7030991.

Berko, J., D. D. Ingram, S. Saha, and J. D. Parker, 2014: Deaths attributed to heat, cold, and other weather events in the United States, 2006-2010. Natl. Health Stat. Rep., 76, 1-15.

Bernhard, M. C., S. T. Kent, M. E. Sloan, M. B. Evans, L. A. McClure, and J. M. Gohlke, 2015: Measuring personal heat exposure in an urban and rural environment. Environ. Res., 137, 410-418, doi:10.1016/j.envres.2014.11.002. 
Boeckmann, M., and I. Rohn, 2014: Is planned adaptation to heat reducing heat-related mortality and illness? A systematic review. BMC Public Health, 14, 1112, doi:10.1186/1471-2458-14-1112.

California Climate Action Team, 2013: Preparing California for extreme heat: Guidance and recommendations. 24 pp. [Available online at http://www.climatechange.ca.gov/climate_action_team/ reports/Preparing_California_for_Extreme_Heat.pdf.]

Chester, M., D. Eisenman, S. Pincetl, A. Fraser, M. Nahlik, and M. Bartos, 2015: Extreme heat vulnerability and urban energy use. Proc. ICIE 2015 (Int. Conf. on Industrial Ecology), Guildford, United Kingdom, International Society for Industrial Ecology.

Chuang, W.-C., P. Gober, W. T. L. Chow, and J. Golden, 2013: Sensitivity to heat: A comparative study of Phoenix, Arizona and Chicago, Illinois (2003-2006). Urban Climate, 5, 1-18, doi:10.1016/j.uclim.2013.07.003.

Curriero, F. C., K. S. Heiner, J. M. Samet, S. L. Zeger, L. Strug, and J. A. Patz, 2002: Temperature and mortality in 11 cities of the eastern United States. Amer. J. Epidemiol., 155, 80-87, doi:10.1093/aje/155.1.80.

Fraser, A. M., M. V. Chester, D. Eisenman, D. M. Hondula, S. S. Pincetl, P. English, and E. Bondank, 2015: Household accessibility to heat refuges: Residential air conditioning, public cooled space, and walkability. Environ. Plann., doi:10.1177/ 0265813516657342, in press.

Harlan, S. L., A. J. Brazel, L. Prashad, W. L. Stefanov, and L. Larsen, 2006: Neighborhood microclimates and vulnerability to heat stress. Soc. Sci. Med., 63, 2847-2863, doi:10.1016/ j.socscimed.2006.07.030.

, J. H. Declet-Barreto, W. L. Stefanov, and D. B. Petitti, 2013: Neighborhood effects on heat deaths: Social and environmental predictors of vulnerability in Maricopa County, Arizona. Environ. Health Perspect., 121, 197-204, doi:10.1289/ehp.1104625.

Hartz, D. A., A. J. Brazel, and J. S. Golden, 2013: A comparative climate analysis of heat-related emergency 911 dispatches: Chicago, Illinois and Phoenix, Arizona USA 2003 to 2006. Int. J. Biometeor., 57, 669-678, doi:10.1007/s00484-012-0593-z.

Hess, J. J., M. Eidson, J. E. Tlumak, K. K. Raab, and G. Luber, 2014: An evidence-based public health approach to climate change adaptation. Environ. Health Perspect., 122, 1177-1186, doi:10.1289/ehp.1307396.

Hondula, D. M., R. C. Balling Jr., J. K. Vanos, and M. Georgescu, 2015a: Rising temperatures, human health, and the role of adaptation. Current Climate Change Rep., 1, 144-154, doi:10.1007/ s40641-015-0016-4.

—, R. E. Davis, M. V. Saha, C. R. Wegner, and L. M. Veazey, 2015b: Geographic dimensions of heat-related mortality in seven U.S. cities. Environ. Res., 138, 439-452, doi:10.1016/j.envres.2015.02.033.

Houghton, A., 2013: Developing climate change environmental public health indicators: Guidance for local health departments. Council of State and Territorial Epidemiologists, $21 \mathrm{pp}$.

Huang, C., P. Vaneckova, X. Wang, G. FitzGerald, Y. Guo, and S. Tong, 2011: Constraints and barriers to public health adaptation to climate change: A review of the literature. Amer. J. Prev. Med., 40, 183-190, doi:10.1016/j.amepre.2010.10.025.

Koplan, J. P., R. L. Milstein, and S. F. Wetterhall, 1999: Framework for program evaluation in public health. Morbidity and Mortality Weekly Report, Vol. 48, Centers for Disease Control, Atlanta, GA, 1-40. [Available online at https://www.cdc.gov/ mmwr/PDF/rr/rr4811.pdf.]

Kuras, E. R., D. M. Hondula, and J. Brown-Saracino, 2015: Heterogeneity in individually experienced temperatures (IETs) within an urban neighborhood: Insights from a new approach to measuring heat exposure. Int. J. Biometeor., 59, 1363-1372, doi:10.1007/s00484-014-0946-x.

MAG, cited 2015: Heat relief regional network. Maricopa County Association of Governments. [Available online at http://www. azmag.gov/heatrelief.]

MCDPH, 2015a: Heat-associated deaths in Maricopa County, AZ: Final report for 2014. Maricopa County Department of Public Health, 28 pp. [Available online at www.maricopa.gov/ PublicHealth/Services/EPI/pdf/heat/2014annualreport.pdf.]

$\ldots$, 2015b: Surviving Arizona's extreme heat. Maricopa County Department of Public Health. [Available online at http://www. maricopa.gov/PublicHealth/Programs/Heat/.]

O'Neill, M. S., A. Zanobetti, and J. Schwartz, 2005: Disparities by race in heat-related mortality in four US cities: The role of air conditioning prevalence. J. Urban Health, 82, 191-197, doi:10.1093/jurban/jti043.

Ostro, B. D., L. A. Roth, R. S. Green, and R. Basu, 2009: Estimating the mortality effect of the July 2006 California heat wave. Environ. Res., 109, 614-619, doi:10.1016/j.envres.2009.03.010.

Pellow, D. N., 2000: Environmental inequality formation: Toward a theory of environmental injustice. Amer. Behav. Sci., 43, 581601, doi:10.1177/0002764200043004004.

Pengelly, L. D., M. E. Campbell, C. S. Cheng, C. Fu, S. E. Gingrich, and R. Macfarlane, 2007: Anatomy of heat waves and mortality in Toronto: Lessons for public health protection. Can. J. Public Health, 98, 364-368.

Reid, C. E., M. S. O'Neill, C. J. Gronlund, S. J. Brines, D. G. Brown, A. V. Diez-Roux, and J. Schwartz, 2009: Mapping community determinants of heat vulnerability. Environ. Health Perspect., 117, 1730-1736, doi:10.1289/ehp.0900683.

Rey, G., E. Jougla, A. Fouillet, G. Pavillon, P. Bessemoulin, P. Frayssinet, J. Clavel, and D. Hémon, 2007: The impact of major heat waves on all-cause and cause-specific mortality in France from 1971 to 2003. Int. Arch. Occup. Environ. Health, 80, 615-626, doi:10.1007/s00420-007-0173-4.

Schwartz, J., J. M. Samet, and J. A. Patz, 2004: Hospital admissions for heart disease: The effects of temperature and humidity. Epidemiology, 15, 755-761, doi:10.1097/01.ede.0000134875.15919.0f.

Semenza, J. C., C. H. Rubin, K. H. Falter, J. D. Selanikio, W. D. Flanders, H. L. Howe, and J. L. Wilhelm, 1996: Heat-related deaths during the July 1995 heat wave in Chicago. N. Engl. J. Med., 335, 84-90, doi:10.1056/NEJM199607113350203.

Tobias, A., B. Armstrong, I. Zuza, A. Gasparrini, C. Linares, and J. Díaz, 2012a: Mortality on extreme heat days using official thresholds in Spain: A multi-city time series analysis. $B M C$ Public Health, 12, 133, doi:10.1186/1471-2458-12-133.

_ J. Díaz, and C. Linares, 2012b: A cautionary note to prevent the heat effects on human health. Sci. Total Environ., 439, 238 239, doi:10.1016/j.scitotenv.2012.09.007.

Uebelherr, J. M., D. M. Hondula, and E. W. Johnston, 2015: Innovative participatory agent based modeling using a complexity governance perspective. Proc. 16th Annual Int. Conf. on Digital Government Research, Phoenix, AZ, Digital Government Society, 307-308.

U.S. Census Bureau, 2010: Profile of general population and housing characteristics, 2010: Maricopa County, Arizona. Accessed 2016. [Available online at http://factfinder.census. gov/faces/nav/jsf/pages/index.xhtml.]

Vaneckova, P., P. J. Beggs, and C. R. Jacobson, 2010: Spatial analysis of heat-related mortality among the elderly between 1993 and 2004 in Sydney, Australia. Soc. Sci. Med., 70, 293 304, doi:10.1016/j.socscimed.2009.09.058.

Woodward, A., and Coauthors, 2014: Climate change and health: On the latest IPCC report. Lancet, 383, 1185-1189, doi:10.1016/ S0140-6736(14)60576-6. 